\title{
Redução de evaporação de água: estudo de caso no reservatório de São Gonçalo/PB
}

As mudanças climáticas têm proporcionado um agravamento da gestão dos recursos hídricos em regiões semiáridas. As disputas pelos diversos usos da água ocasionam conflitos entre os usuários e as elevadas taxas de evaporação, presentes nessas regiões, contribuem de forma significativa para o agravamento das crises hídricas. A redução das taxas de evaporação em reservatórios nessas regiões surge como mais uma forma de aumentar a oferta de água, mediante a aplicação de diferentes técnicas, utilizando-se diferentes materiais, cada qual adequado ao caso específico. 0 estudo objetiva analisar a redução de evaporação de água no reservatório de São Gonçalo, PB no semiárido nordestino a partir da utilização de várias técnicas sugeridas na literatura. Foram realizadas simulações com quatro diferentes técnicas de redução da evaporação no reservatório São Gonçalo, situado na região semiárida do Estado da Paraíba, Brasil. Os resultados demonstraram que o uso de bolas de polietileno apresentou o melhor índice de redução da evaporação, entretanto sua utilização é recomendável quando o reservatório apresentar baixos níveis do volume de água, devido ao seu maior custo de implementação e de manutenção. A técnica de quebra vento apresentou um índice satisfatório de redução da evaporação sendo recomendada para a região em estudo devido ao seu baixo custo de implementação e de manutenção, não ocasionando impactos ao corpo hídrico. No entanto, tornam-se necessários a realização de estudos mais aprofundados, buscando identificar possíveis impactos ambientais não só no corpo hídrico, mas na região no entorno do reservatório.

Palavras-chave: Aumento da Oferta Hídrica; Convivência com o Semiárido; Sustentabilidade.

\section{Water evaporation reduction: case study in São Gonçalo reservoir/PB}

\begin{abstract}
Climate changes have provided a worsening of the management of water resources in semiarid regions. Disputes over the various uses of water cause conflicts between users and high evaporation rates, present in these regions, contribute significantly to the worsening of water crisis. The reduction of evaporation rates in reservoirs in these regions appears as another way to increase the supply of water, through of different techniques application, using different materials, each one adapted to the specific case. The study aims to analyze the reduction of water evaporation in the reservoir of São Gonçalo, PB in the northeastern semiarid from the use of various techniques suggested in the literature. It was realized simulations with four different techniques of evaporation reduction in the São Gonçalo reservoir, located in the semi-arid region of Paraiba State. The results showed that the use of polyethylene balls presented the best evaporation reduction index, however its use is recommended when the reservoir presents low levels of water volumedue to its higher implementation and maintenance cost.The wind breaking technique showed a satisfactory evaporation reduction indexbeing recommended for the study region due to its low implementation and maintenance cost, not causing impacts to the water body. However, further studies have to be conducted, aiming the identification of possible environmental impacts not only in the water body, but in the region surrounding the reservoir.
\end{abstract}

Keywords: Increase in Water Supply; Living With Semiarid; Sustainability.

Topic: Engenharia da Sustentabilidade e Meio Ambiente

Reviewed anonymously in the process of blind peer

Paulo Abrantes de Oliveira

Universidade Federal de Campina Grande, Brasil

http://lattes.cnpq.br/1568831732529530

http://orcid.org/0000-0003-2927-0867

barionix01@gmail.com

Valterlin da Silva Santos (id

Universidade Federal de Campina Grande, Brasil

http://lattes.cnpq.br/4740303724015282

http://orcid.org/0000-0002-4789-2937

valterlin@yahoo.com.br

Rosires Catão Curi (iD

University of Waterloo, Canadá

http://lattes.cnpq.br/7625445154639508

http://orcid.org/0000-0001-6924-4204

rosirescuri@yahoo.com.br

d

DOI: 10.6008/CBPC2179-6858.2019.005.0018
Received: 12/08/2019

Approved: 27/09/2019
José Ribamar Marques de Carvalho

Universidade Federal de Campina Grande, Brasil

http://lattes.cnpq.br/6335184086197610

http://orcid.org/0000-0003-3482-9231

profribamar@gmail.com
Referencing this:

OLIVEIRA, P. A.; SANTOS, V. S.; CURI, R. C.; CARVALHO, J. R. M. Redução de evaporação de água: estudo de caso no reservatório de São Gonçalo/PB. Revista Ibero Americana de Ciências Ambientais, v.10, n.5, p.204-217, 2019. DOI: http://doi.org/10.6008/CBPC21796858.2019 .005 .0018 


\section{INTRODUÇÃO}

A água possui importância vital na criação e manutenção das mais variadas espécies de vida, devido aos seus diversos usos e pode ser considerado um elemento fundamental para o desenvolvimento econômico, social e ambiental de uma nação. O Brasil possui $12 \%$ das reservas de água doce do mundo. No entanto, devido às suas dimensões continentais, características topográficas e climáticas, a abundância desse recurso está localizada em regiões com baixa densidade populacional e distante dos grandes centros urbanos (OECD, 2015).

A região semiárida do nordeste do Brasil é caracterizada pela alta densidade populacional, elevada evaporação, alternância das estações de baixa incidência pluviométrica e de abundante precipitação, originadas de condições climáticas e hidrológicas adversas, potencializada por períodos de estiagem(secas) frequentes e que provocam enormes prejuízos econômicos, sociais e ambientais (GHEYI et al., 2012).

A precipitação média anual nessa região é de $750 \mathrm{~mm}$, índice que a eleva a categoria de uma das regiões semiáridas mais chuvosas do planeta. No entanto, em algumas áreas, a precipitação média não ultrapassa os $400 \mathrm{~mm}$ anuais. Somando-se a isso, tem-se que a evapotranspiração potencial médio atinge $2.500 \mathrm{~mm}$ ano, gerando elevados déficits hídricos e limitando os cultivos agrícolas de sequeiro (GHEYI et al., 2012). Este déficit favorece o aumento da concentração de sais nos corpos hídricos superficiais, degradando a qualidade das águas, por meio da eutrofização e salinização (ARAÚJO et al., 2011).

As estratégias de mitigação de secas, na região Nordeste do Brasil, evoluíram em decorrência dos impactos sociais provocados pela seca de 1877-1879. Destaca-se que, ainda na fase do Império do Brasil, predominaram as políticas assistencialistas de distribuição de alimentos aos necessitados, criação de frente de emergências de trabalho, importação de camelos do continente africano para o estado do Ceará, adaptação de plantas resistentes à estiagem. Deve-se destacar que, nessa fase foi construído o Açude do Cedro no Ceará, considerado a primeira grande obra de combate às secas (MELO, 1999).

Com a proclamação da República, novamente as atenções voltaram-se para a construção de obras que permitissem o 'combate à seca'. Assim, neste período foi criado em 1909, o Instituto de Obras Contra as Secas (IOCS), o qual se referia à categoria geográfica Nordeste, como o espaço onde se concentravam as áreas que sofriam com os efeitos das longas estiagens. Dez anos depois, o IOCS tornou-se o Instituto Federal (IFOCS), precursor do atual Departamento Nacional de Obras Contra as Secas (DNOCS), criado em 1945 em atividade até os dias atuais (ALBUQUERQUE JUNIOR, 2009).

Devido às diferenças sociais e econômicas existentes entre as várias regiões do Brasil, foi criada em 15 de dezembro de 1959, a Superintendência do Desenvolvimento do Nordeste - SUDENE. Neste contexto, considerou-se como uma forma de intervenção do Estado brasileiro na região Nordeste, com o objetivo de promover e coordenar o desenvolvimento da região. Num primeiro momento, a intervenção nesta região deu-se pela construção de grandes obras hídricas (Política de Açudagem), que segundo dados do DNOCS, transformaram a região nordeste do Brasil no maior canteiro de obras da América Latina (VILLA, 2000).

Para Rebouças et al. (1976) e Suassuna (2002) a política de construção de açudes fundamenta-se no 
binômio seca/falta de água, tendo como solução a construção de reservatórios para a acumulação de água em grandes quantidades, o que na literatura científica ficou conhecido como a solução hidráulica. Segundo estudos de Suassuna (2002) estima-se que seja em torno de70 milhões o número de açudes existentes na região semiárida nordestina, caracterizados predominantemente, por capacidade de acumulação entre 10.000 e $200.000 \mathrm{~m}^{3}$. Estes reservatórios representam $80 \%$ dos corpos d'água artificiais dessa região, colocando-a entre as maiores acumuladoras de água em reservatórios artificiais do mundo.

Devido às condições climáticas peculiares do semiárido, estudos científicos realizados por Rebouças et al. (1976), Molle et al. (1992) e Suassuna (2002) estipulam que a evaporação na região Nordeste do Brasil é responsável pela perda de grande volume de água armazenada. Segundo estes autores, a evaporação varia de $1000 \mathrm{~mm} /$ ano no litoral da Bahia a Recife/PE, elevando-se para 3000 mm/ano na região de Petrolina-PE. Estudos realizados em diversas regiões do semiárido nordestino apontam que cerca de $40 \%$ das águas acumuladas em reservatórios perdem-se através do processo evaporativo (SUASSUNA, 2002).

Diante dos dados acima declinados, percebe-se a relevância da análise acerca da efetivação de técnicas que possibilitem minimizar as perdas evaporativas em reservatórios artificiais, de pequeno, médio e de grande porte, em regiões semiáridas. Os estudos científicos comprovaram que a adoção de algumas técnicas, a saber: quebra-ventos, corpos artificiais flutuantes, plantas aquáticas, painéis flutuantes de energia fotovoltaica, filmes monomoleculares e armazenamento subterrâneo surgem como mais uma alternativa capaz de maximizar a oferta hídrica nessas regiões.

Face ao exposto, o problema de pesquisa busca responder ao seguinte questionamento: analisar a redução de evaporação de água no reservatório de São Gonçalo/PB no semiárido nordestino a partir da utilização de várias técnicas sugeridas na literatura?. Para tanto, objetiva analisar a redução de evaporação de água no reservatório de São Gonçalo, PB no semiárido nordestino a partir da utilização de várias técnicas sugeridas na literatura.

\section{REVISÃO TÓRICA}

\section{Técnicas de redução da evaporação em reservatórios de água}

A utilização de técnicas visando reduzir a evaporação em lagos não é algo novo, a literatura científica está permeada de descrições de uma gama de experimentos buscando atingir este propósito. Silans (2003) descreve a utilização de uma série de técnicas em diferentes partes do mundo, tendo como objetivo o estudo da redução da evaporação em reservatórios de água. Assim, Estes experimentos utilizavam: quebra-ventos; corpos artificiais flutuantes à superfície; plantas aquáticas de folhas flutuantes na superfície; painéis de energia fotovoltaica flutuantes; filmes monomoleculares de álcoois gordurosos e armazenamento subterrâneo. Os mecanismos acima citados diferem, na forma, como interferem na dinâmica da evaporação. Ademais, deve-se destacar que alguns reduzem a velocidade do vento, outros refletem a energia solar incidente, os últimos provocam o aumento da tensão superficial, modificando a interação entre a água e a atmosfera e, por conseguinte, reduzindo as trocas de energia entre a superfície da água e a atmosfera. A 
primeira técnica a ser analisada se constitui de uma barreira física colocada no entorno do corpo hídrico, como forma de minimizar a ação do vento no processo evaporativo, comumente denominada de 'quebra ventos' (Figura 1), podendo ser usadas árvores de grande porte, plantadas em volta do reservatório.

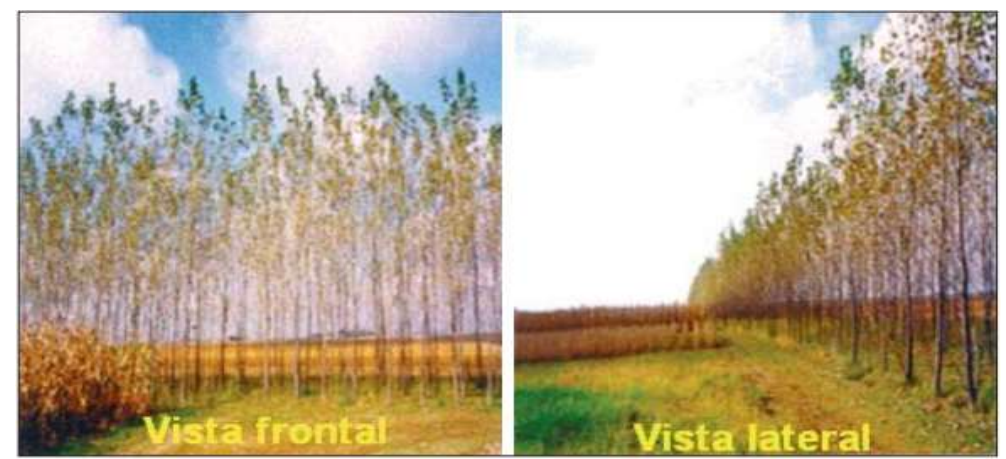

Figura 1: Eucalipto utilizado como quebra vento. Fonte: Schoffel (2009).

Segundo Schoffel (2009) e Helfer et al. (2011) esta técnica possui vantagens e desvantagens. As vantagens destacam-se pela boa eficiência $(35 \%)$ na redução da evaporação e baixa manutenção. No entanto, as desvantagens surgem no alto custo de implantação e na escolha das espécies vegetais adaptadas às condições locais. A eficiência de um quebra-vento na redução da velocidade do vento depende principalmente da sua permeabilidade, da altura e da sua orientação em relação ao vento. As espécies Acácia (Acaciasp), Eucalipto (Eucalyptusspp), Leucena (Leucaenaleucocephala), Algaroba (Prosopisjuliflora) podem ser usadas na região semiárida (CONCEIÇÃO, 1986; LEAL, 2009; NICODEMO, 2009; SCHOFFEL, 2009; FRANÇA et al., 2010).

A segunda técnica utilizada como redutor evaporativo em lagos ou reservatórios de água é a inserção de corpos artificiais flutuantes na superfície da água do reservatório, com o intuito de reduzir a incidência do vento e dos raios solares, refletindo-os de volta para a atmosfera (MARINHO et al., 2015). Os materiais mais utilizados são: placas de isopor, bolas de polietileno, hexágonos de plástico, telas de nylon, painéis flutuantes de geração de energia solar.

A utilização de bolas de polietileno (Figura 2) foi testada no Estado Americano da Califórnia, tendo sido muito divulgada pela mídia como alternativa para a crise hídrica que assola aquele Estado. A adoção desse método também possui vantagens e desvantagens. As vantagens aparecem na sua alta eficiência aproximadamente (95\%). No entanto, a sua utilização requer um alto custo na aquisição e manutenção dos corpos artificiais que flutuam na superfície do lago (MARINHO et al., 2015).

A implantação de usinas de geração de energia solar flutuantes, nos espelhos d'água dos reservatórios (Figura 3) surge como uma inovação tecnológica de dupla vantagem, na medida em que seus painéis solares reduzem a evaporação da água nos lagos. Essas mesmas estruturas convertem a energia fotovoltaica em energia elétrica, sendo considerada uma fonte alternativa não poluente. 


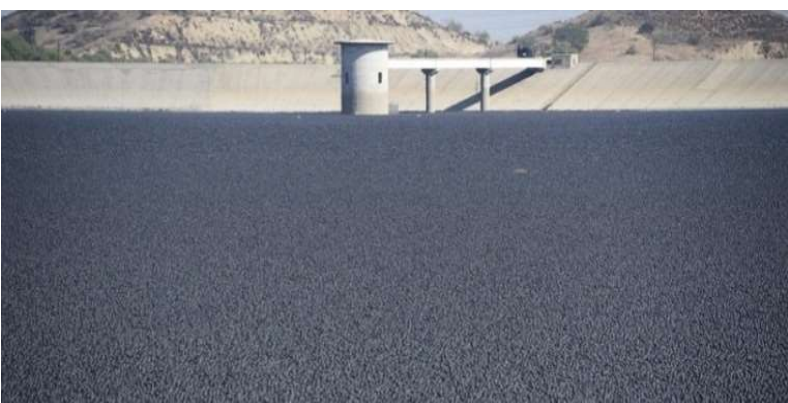

Figura 2: Bolas flutuantes utilizadas como redutor de evaporação na Califórnia-EUA. Fonte: Blevins et al. (2015).

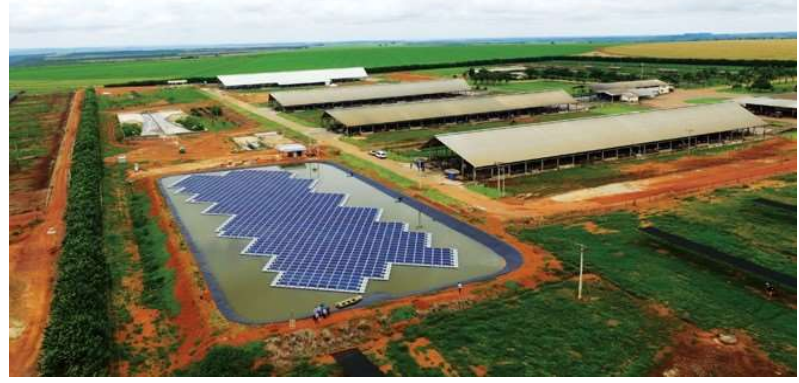

Figura 3: Painéis solares utilizados como redutores de evaporação e geradores de eletricidade. Fonte: MTEC (2017).

A terceira técnica a ser analisada constitui no emprego de plantas aquáticas de folhas flutuantes, na superfície do reservatório (Figura 4) com o intuito de reduzir a influência do vento e da radiação solar no processo evaporativo. As espécies mais utilizadas são: Nymphaeaalba, Nymphoidesíndica e Jussieua (LudwigiaNatanssp). Estas espécies apresentam características positivas para a redução da evaporação, pois flutuam na superfície sem aumentar a superfície evaporativa, são brilhosas, que é condição essencial para a reflexão de parte da radiação solar e a superfície das folhas é repelente de água e inibe a deposição de poeira (SILANS, 2003).

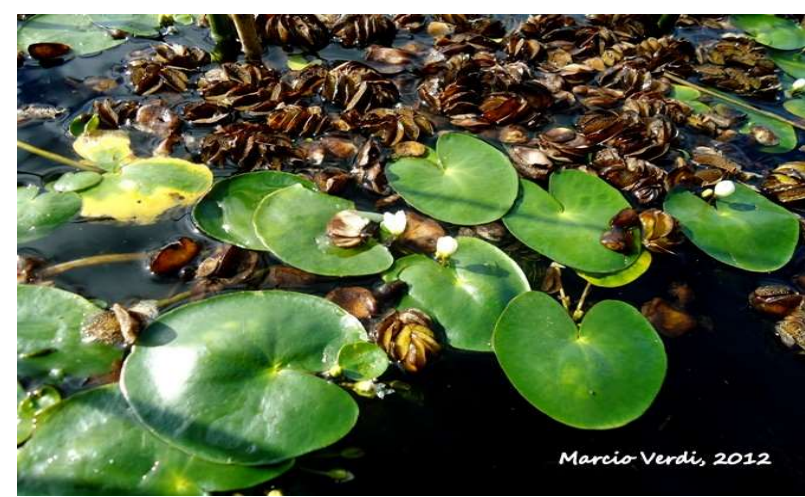

Figura 4: Plantas aquáticas de folhas flutuantes. Fonte: Verdi (2012).

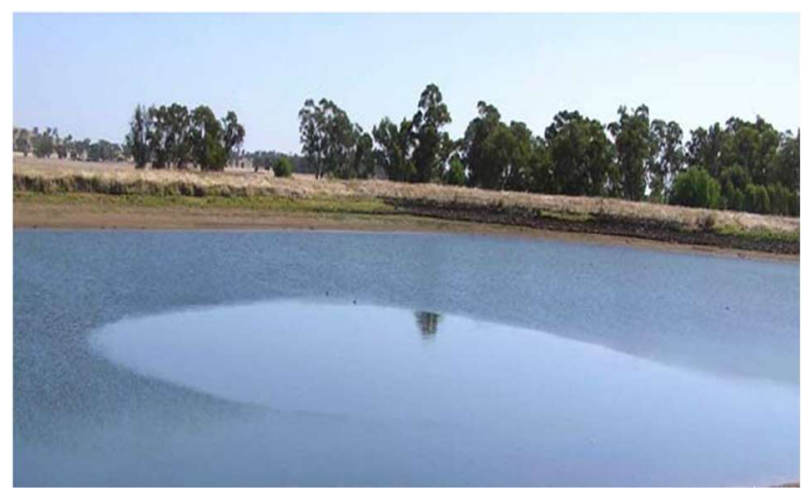

Figura 5: Filmes monomoleculares utilizados em reservatório de água. Fonte: Craig et al. (2007).

As vantagens na utilização dessa técnica estão no seu baixo custo, pois se referem à espécies bem conhecidas e resistentes nas mais variadas condições de clima. As desvantagens ocasionadas pela sua utilização dizem respeito à sua baixa eficiência (18\%) e a alteração das características da água (MARINHO et al., 2015; SILANS, 2003). A quarta técnica analisada são os filmes monomoleculares de álcoois gordurosos (Figura 5), que atuam aumentando a tensão superficial da água, reduzindo a difusão molecular e a evaporação.

As experiências realizadas em várias partes do mundo têm mostrado que um composto químico chamado de álcool cetílico hexadeconal ou derivados de sebo, óleo de coco ou óleo de palma é capaz de formar uma película monomolecular sobre a superfície da água. Este material é relativamente insípido, inodoro e permite a passagem do oxigênio e do dióxido de carbono, não apresentando toxidade para os seres vivos.

Este composto apresenta uma peculiaridade devido à dupla polaridade de sua molécula, em uma 
extremidade a molécula é hidrofílica e, por conseguinte, apresenta uma grande afinidade de atração com a água, enquanto que a outra extremidade é hidrofóbica e possui repulsão com as moléculas de água (SAGGAï et al., 2014). A principal vantagem dessa técnica é a boa eficiência (43\%), pois os compostos químicos empregados no filme são biodegradáveis. As desvantagens encontram-se na necessidade de reaplicação das substâncias químicas em decorrência da interação desses compostos com a poeira carregada pelo vento e o aumento da temperatura da água. Segundo Silans (2003), a substância mais usada tem sido o álcool cetílico (hexadecanol). O Quadro 1 apresenta o comparativo entre diferentes técnicas de redução de evaporação em reservatórios de água, considerando variáveis econômicas, ambientais, destacando-se o seu percentual de eficiência.

\section{MATERIAIS E MÉTODOS}

Com o intuito de avaliar algumas técnicas de redução da evaporação foram realizadas simulações no reservatório São Gonçalo (Figura 6), situado na região semiárida do Estado da Paraíba. Faz parte da bacia hidrográfica do Rio Piranhas-Açú, na Região do Alto Curso do rio Piranhas nas divisas dos municípios de Sousa e Marizópolis ambas no estado da Paraíba.

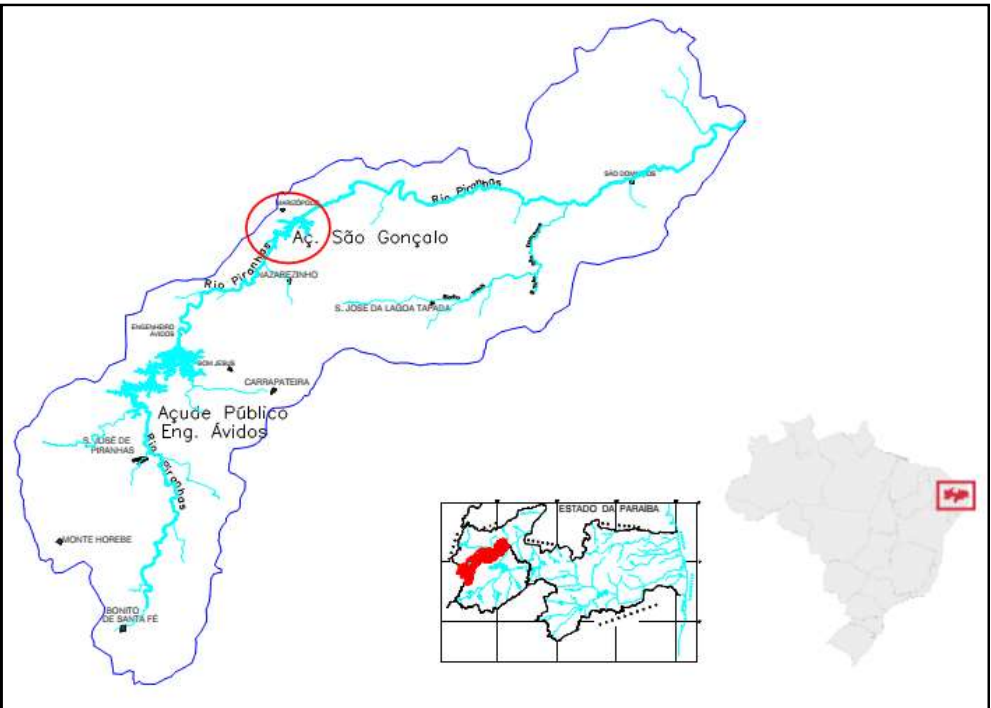

Figura 6: Localização do Reservatório São Gonçalo no sertão do Estado da Paraíba, Brasil. Fonte: Adaptado de SCIENTEC (1997).

O reservatório São Gonçalo teve sua construção iniciada em 1935 com o intuito de diminuir os problemas com a disponibilidade hídrica e auxiliar no desenvolvimento econômico da região. A Tabela 1 apresenta alguns dados técnicos do reservatório São Gonçalo. O Departamento Nacional de Obras Contra as Secas (DNOCS) juntamente com a Agência Nacional de Águas (ANA) são responsáveis gerenciamento dos múltiplos usos da água no referido reservatório. Já Agência Executiva de Gestão das Águas do Estado da Paraíba (AESA) é responsável pelo monitoramento.

A principal finalidade do reservatório é o abastecimento humano das cidades de Sousa, Marizópolis e Nazarezinho, do Distrito São Gonçalo, dos Núcleos Habitacionais I, II e III, e de comunidades localizadas no entorno do reservatório. Além disso, o reservatório supre a demanda hídrica de áreas agrícolas no seu 
entorno e do Perímetro Irrigado de São Gonçalo, que possui uma área total de 3.139 ha, onde são desenvolvidas diversas culturas agrícolas, tanto permanentes (coco, banana, capim, goiaba, acerola, manga, graviola e caju), quanto temporárias (milho, feijão e batata) (BATISTA, 2013; OLIVEIRA, 2015).

Tabela 1: Dados referentes ao Reservatório São Gonçalo.

\begin{tabular}{|l|l|}
\hline Volume máximo $\left(10^{6} \mathrm{~m}^{3}\right)$ & 44,6 \\
\hline Volume morto $\left(10^{6} \mathrm{~m}^{3}\right)$ & 2,982 \\
\hline Material & Terra \\
\hline Área da bacia hidráulica (ha) & 700 \\
\hline Área da bacia hidrográfica $\left(\mathrm{km}^{2}\right)$ & 315 \\
\hline Largura do vertedor $(\mathrm{m})$ & 230 \\
\hline Vazão máxima - vertedor $\left(\mathrm{m}^{3} / \mathrm{s}\right)$ & 1.800 \\
\hline
\end{tabular}

Fonte: Adaptado de SCIENTEC (1997).

Quadro 1: Relação entre as diferentes técnicas de redução de evaporação e variáveis econômicas, ambientais e eficiência.

\begin{tabular}{|c|c|c|c|c|c|}
\hline Técnica & Eficiência & $\begin{array}{l}\text { Custo } \\
\text { Implantação }\end{array}$ & $\begin{array}{ll}\text { Custo } & \text { de } \\
\text { manutenção } & \end{array}$ & $\begin{array}{l}\text { Impacto no corpo } \\
\text { hídrico }\end{array}$ & $\begin{array}{ll}\text { Porte } & \text { do } \\
\text { reservatório }\end{array}$ \\
\hline Quebra vento & $35 \%$ & Médio & Baixo & Nenhum & Pequeno a grande \\
\hline \multicolumn{6}{|l|}{ Corpos Flutuantes } \\
\hline Bolas Plásticas & $95 \%$ & Alto & Alto & Baixo & Pequeno a grande \\
\hline Placas solares & $70 \%$ & Alto & Baixo & Baixo & Pequeno \\
\hline Placas de isopor & $45 \%$ & Médio & Baixo & Baixo & Pequeno \\
\hline Hexágonos & $80 \%$ & Alto & Baixo & Baixo & Pequeno \\
\hline Telas de nylon & $30 \%$ & Alto & Alto & Baixo & Pequeno \\
\hline Plantas aquáticas & $18 \%$ & Baixo & Alto & Médio a Alto & Pequeno \\
\hline $\begin{array}{l}\text { Filmes } \\
\text { monomoleculares }\end{array}$ & $43 \%$ & Alto & Alto & Médio a Alto & Pequeno \\
\hline
\end{tabular}

Entretanto, o crescimento econômico, populacional e o aumento das atividades agrícolas vêm acarretando uma pressão maior sobre o reservatório, ocasionando falhas no atendimento de suas demandas, tanto para o abastecimento humano quanto para a irrigação. Desde 2012 a região do reservatório está sofrendo com as consequências da pior seca dos últimos 50 anos. O reservatório São Gonçalo entrou em colapso em agosto de 2015, as populações da zona rural e das cidades abastecidas pelo reservatório sofreram com um racionamento de água, sendo que desde janeiro de 2015 está suspensa por ordem judicial a retirada de água do reservatório para a irrigação de culturas agrícolas (SANTOS et al., 2017; ABRANTES, 2017).

\section{Cenários Propostos do Uso das Técnicas de Redução da Evaporação}

Para a realização das simulações das técnicas de redução da evaporação no reservatório São Gonçalo foram propostos os seguintes cenários: Cenário C1: Foi utilizado uma simulação com o uso de quebra vento para reduzir a evaporação do reservatório; Cenário C2: Foi utilizado uma simulação com o uso de bolas de polietileno para reduzir a evaporação do reservatório; Cenário C3: Foi utilizado uma simulação com o uso de plantas aquáticas de folhas flutuantes para reduzir a evaporação do reservatório; Cenário C4: Foi utilizado uma simulação com o uso filmes monomoleculares de álcoois gordurosos para reduzir a evaporação do reservatório.

\section{Modelo de Simulação Utilizado}

Com a finalidade de verificar o volume de água acumulado e o volume de água evaporado em cada 
cenário proposto foi realizado a simulação da operação do reservatório utilizando o seguinte modelo:

$$
\begin{aligned}
& \operatorname{Vr}(\mathrm{t})=\operatorname{Vr}(\mathrm{t}-1)+\mathrm{Qa}(\mathrm{t})-\mathrm{R}(\mathrm{t})-\operatorname{Evr}(\mathrm{t})-\mathrm{Qv}(\mathrm{t}) \\
& \operatorname{Vrmin} \leq \operatorname{Vr}(\mathrm{t}) \leq \operatorname{Vrmax} \\
& 0 \leq \mathrm{Qv}(\mathrm{t}) \leq \mathrm{Qvmax}
\end{aligned}
$$

Sendo:

$\operatorname{Vr}(\mathrm{t}-1)$ o volume de água do reservatório no início do mês $\mathrm{t}_{i}$ $\mathrm{Vr}(\mathrm{t})$ o volume de água do reservatório no final do mês $\mathrm{t}$; $\mathrm{Qa}(\mathrm{t})$ a vazão afluente ao reservatório durante o mês $\mathrm{t}$; $\mathrm{R}(\mathrm{t})$ o volume de água retirado de água do reservatório durante o mês $\mathrm{t}$; Evr(t) o volume de água evaporado no reservatório durante o mês t; $\mathrm{Qv}(\mathrm{t})$ o volume de água vertido do reservatório durante o mês t; Vrmin o volume mínimo de água (ou morto) do reservatório; Vrmax a capacidade máxima de água do reservatório; Qvmax o volume máximo de água que pode passar pelo vertedouro.

\section{Dados do Sistema}

Para a realização das simulações dos cenários propostos se utilizou o período de agosto de 2017 a janeiro de 2019 por apresentarem uma serie contínua de dados. A Figura 7 apresenta o volume de água do reservatório São Gonçalo no período estudado.

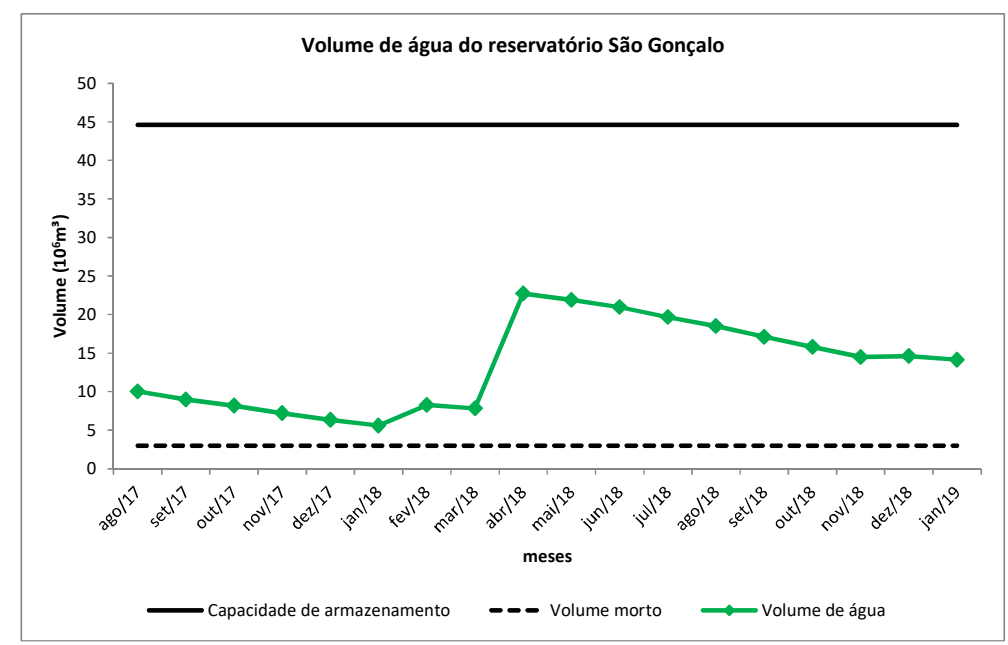

Figura 7: Volume de água do reservatório São Gonçalo no período estudado. Fonte: AESA (2019).

Observa-se que no período analisado o volume de água não atingiu a capacidade máxima de armazenamento, não havendo, portanto, volume vertido nesse período. Entre outubro de 2017 a março de 2018 o volume de água do reservatório esteve abaixo de $20 \%$ da capacidade de armazenamento, atingindo o valor de $12 \%$ da capacidade máxima de armazenamento em janeiro de 2018 . No mês de abril 2018, o reservatório recebeu uma grande quantidade de água o que elevou o volume de água para o valor de 22,72 milhões de $\mathrm{m}^{3}$ (cerca $51 \%$ da capacidade máxima de armazenamento), em seguida o volume de água foi decrescendo devido às retiradas de água do reservatório para satisfazer as demandas dos vários usos, e em decorrência das perdas por evaporação.

Para a estimativa do volume evaporado do reservatório no ano de 2018 utilizou-se a com a Equação (4):

$$
\operatorname{Evr}(t)=\operatorname{er}(t) \cdot k t(t) \cdot 0,5 \cdot[\operatorname{Ar}(t)+\operatorname{Ar}(t-1)]
$$


Sendo: $\operatorname{Ar}(\mathrm{t}-1)$ a área do espelho d'água do reservatório no início do mês t;

$\operatorname{Ar}(\mathrm{t})$ a área do espelho d'água do reservatório no final do mês $\mathrm{t}$; er(t) a taxa de evaporação do Tanque 'Classe $A$ ' no mês te;

$k t(t)$ o coeficiente de Tanque 'Classe A' no mês t.

Os dados da curva cota-área-volume do reservatório foram obtidos do Cadastro de Açude do Plano Diretor de Recursos Hídricos da Paraíba: Bacias do Rio Piancó e do Alto Piranhas (SCIENTEC, 1997). Os dados da taxa de evaporação foram obtidos da Estação Climatológica de São Gonçalo (Tabela 2). Os valores mensais do coeficiente Tanque 'Classe A' foram estimados por Oliveira et al. (2005) para a região do sertão paraibano (mais precisamente na cidade de Patos, PB). A Figura 7 apresenta os volumes evaporados de água estimados para o reservatório São Gonçalo no período estudado.

Tabela 2: Taxa de evaporação média mensal Tanque Classe A da Estação Climatológica de São Gonçalo e coeficiente de tanque.

\begin{tabular}{|l|l|l|}
\hline Meses & er $\left.^{\mathbf{1}} \mathbf{( m )}\right)$ & $\mathbf{k t}^{\mathbf{2}}$ \\
\hline Jan & 300,7 & 0,77 \\
\hline Fev & 213,9 & 0,79 \\
\hline Mar & 195,5 & 0,78 \\
\hline Abr & 170,0 & 0,92 \\
\hline Mai & 183,1 & 0,93 \\
\hline Jun & 176,0 & 0,91 \\
\hline Jul & 216,4 & 0,80 \\
\hline Ago & 274,8 & 0,81 \\
\hline Set & 315,1 & 0,77 \\
\hline Out & 344,7 & 0,78 \\
\hline Nov & 333,9 & 0,76 \\
\hline Dez & 332,5 & 0,76 \\
\hline
\end{tabular}

Fonte: SCIENTEC (1997) e Oliveira et al. (2005).

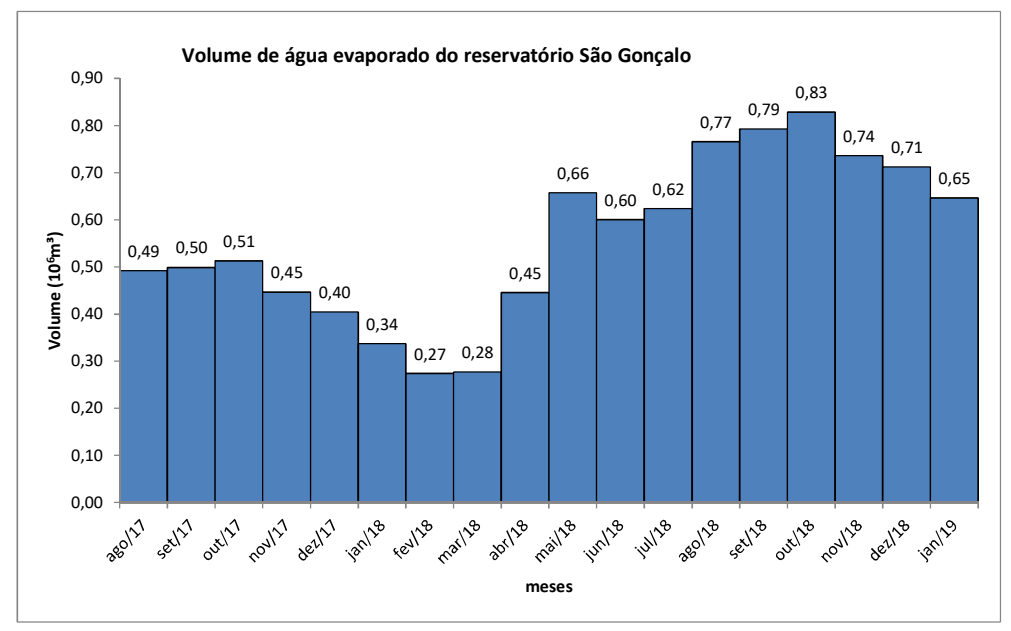

Figura 7: Volume evaporado de água do reservatório São Gonçalo no período estudado.

Tem-se que os maiores volumes evaporados ocorreram entre agosto e dezembro de 2018, principalmente devido às maiores taxas de evaporação e uma maior área do espelho d'água do reservatório nesse período. Os menores volumes de água evaporada ocorreram nos meses de fevereiro e março de 2018 devido às menores taxas de evaporação.

Comparando os volumes de água evaporados no período de agosto a dezembro de 2017 a 2018 temse um aumento de mais de $60 \%$ do volume de água evaporado devido ao aumento da área do espelho d’água. Em relação aos volumes de água evaporados no mês de janeiro de 2018 e janeiro 2019, o aumento foi de mais 90\%, o que evidencia a importância do uso de técnicas para reduzir o volume evaporado de 
reservatórios na região semiárida estudada.

As principais retiradas de água do reservatório no período estudado dizem respeito ao abastecimento das cidades de Sousa, Marizópolis e Nazarezinho, do Distrito São Gonçalo, dos Núcleos Habitacionais I, II e III, e o atendimento de comunidades localizadas no entorno do reservatório, como podem ser observadas na Tabela 3.

Tabela 3: Retirada de água do reservatório São Gonçalo no período estudado (L/s).

\begin{tabular}{|l|l|l|l|}
\hline Meses & Sousa e Marizópolis & Nazarezinho & Entorno* \\
\hline Ago/17 & 160.0 & 7.0 & 7,6 \\
\hline Set/17 & 153.0 & 6.0 & 7,6 \\
\hline Out/17 & 160.0 & 7.0 & 7,6 \\
\hline Nov/17 & 161.0 & 7.0 & 7,6 \\
\hline Dez/17 & 154.0 & 7.0 & 7,6 \\
\hline Jan/18 & 160,0 & 7,0 & 7,6 \\
\hline Fev/18 & 140,0 & 7,0 & 7,6 \\
\hline Mar/18 & 153,0 & 7,0 & 7,6 \\
\hline Abr/18 & 160,0 & 6,0 & 7,6 \\
\hline Mai/18 & 165,0 & 7,0 & 7,6 \\
\hline Jun/18 & 155,0 & 10,0 & 7,6 \\
\hline Jul/18 & 152,0 & 7,0 & 103,0 \\
\hline Ago/18 & 156,0 & 7,0 & 103,0 \\
\hline Set/18 & 151,0 & 7,0 & 103,0 \\
\hline Out/18 & 160,0 & 8,0 & 103,0 \\
\hline Nov/18 & 166,0 & 8,0 & 103,0 \\
\hline Dez/18 & 158,0 & 7,0 & 103,0 \\
\hline Jan/19 & 157,0 & 6,0 & 103,0 \\
\hline
\end{tabular}

Fonte: ANA (2019). OBS: *valores estimados.

A partir de julho de 2018 foi permitida a irrigação de áreas localizadas no entorno do reservatório. Constata-se que o volume de água evaporado no reservatório no período estudado é praticamente igual ao volume de água retirado para o abastecimento humano e irrigação das áreas no entorno do reservatório. Entretanto, no período entre agosto a dezembro de 2018, o volume de água evaporado foi $8 \%$ maior do que o volume de água retirado do reservatório. Destarte, estimou-se a vazão afluente ao reservatório no período estudado com base na Equação (5).

$$
\mathrm{Q} a(\mathrm{t})=\operatorname{Vr}(\mathrm{t})-\mathrm{Vr}(\mathrm{t}-1)+\mathrm{R}(\mathrm{t})+\mathrm{Evr}(\mathrm{t})
$$

Sendo: $\operatorname{Vr}(\mathrm{t}-1)$ o volume de água do reservatório no início do mês $\mathrm{t}$; $\operatorname{Vr}(\mathrm{t})$ o volume de água do reservatório no final do mês $\mathrm{t}$; $\mathrm{Qa}(\mathrm{t})$ a vazão afluente ao reservatório durante o mês t; $\mathrm{R}(\mathrm{t})$ o volume de água retirado de água do reservatório durante o mês $\mathrm{t}$; Evr(t) o volume de água evaporado no reservatório durante o mês $\mathrm{t}$;

A Figura 8 apresenta a vazão afluente estimada para o reservatório São Gonçalo no período estudado. Observa-se que as maiores vazão afluente ao reservatório ocorreram em fevereiro e abril (período chuvoso da região) sendo que de agosto de 2017 a janeiro de 2018 e de maio a novembro 2018 praticamente o reservatório não recebeu água. 


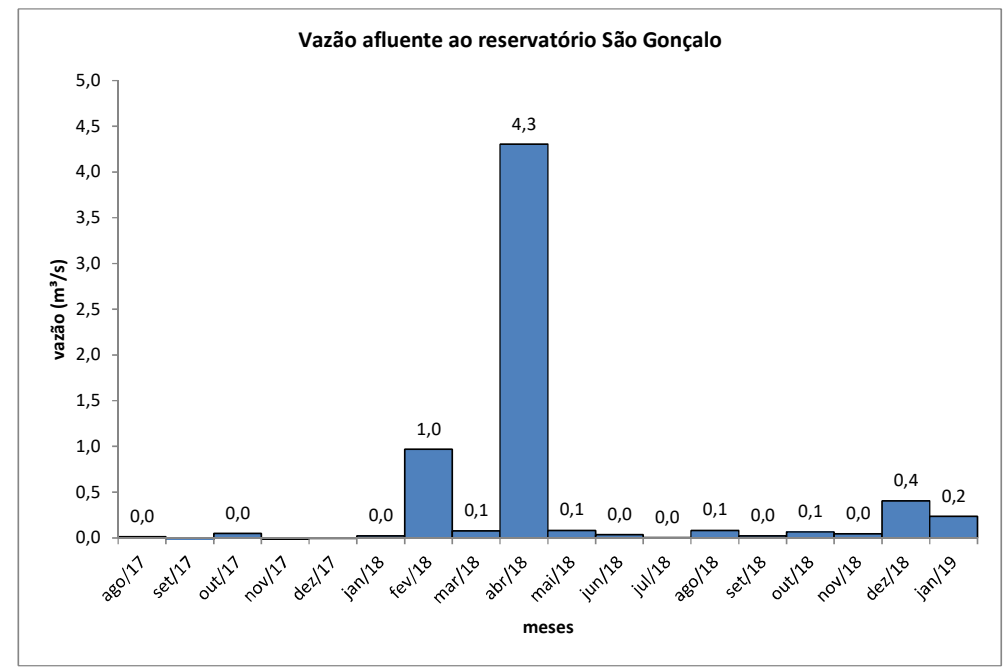

Figura 8: Vazão afluente ao reservatório São Gonçalo no período estudado.

\section{RESULTADOS E DISCUSSÃO}

A Figura 9 apresenta os volumes de água evaporados do reservatório São Gonçalo obtidos com a simulação de cada cenário analisado. Tem-se que todas as técnicas de redução da evaporação avaliadas apresentaram volumes de água evaporados menores que o observado.

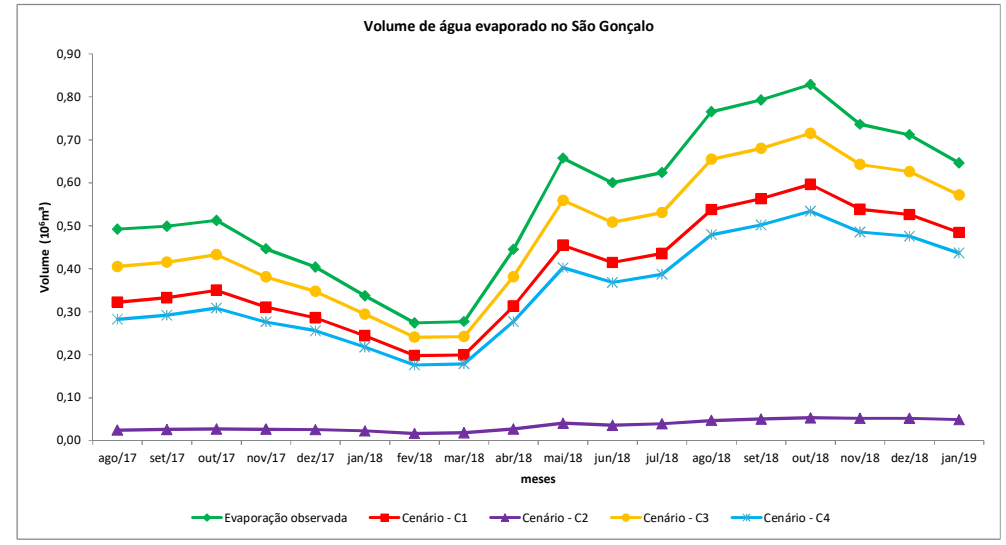

Figura 9: Volume de água evaporado do reservatório São Gonçalo para cada cenário analisado.

Destaque-se o uso de bolas de polietileno (Cenário C2) no qual o volume total evaporado no ano foi de 0,64 milhões de $\mathrm{m}^{3}$ de água (redução de $94 \%$ no volume de água evaporado comparado com o volume evaporado observado). Convém lembrar que tal técnica apresenta um alto custo de implementação e manutenção (MARINHO et al., 2015), o que supostamente se tornaria inviável a sua implementação no contexto geográfico estudado.

Outra técnica de redução da evaporação em destaque foi a utilização filmes monomoleculares de álcoois gordurosos (Cenário C4) que reduziu cerca de $37 \%$ o volume de água evaporado comparado com o volume evaporado observado. Entretanto, tal técnica também apresenta um alto custo de implementação e manutenção além de causar impactos consideráveis no corpo hídrico (SAGGAï et al., 2014), o que também inviabiliza sua implantação efetiva.

A técnica de quebra vento (Cenário $\mathrm{C} 1$ ) apresentou uma redução de cerca $30 \%$ no volume de água evaporado, comparado com o volume evaporado observado. Tal técnica pode ser viável para a região devido 
ao seu baixo custo implementação e manutenção, não ocasionando impactos ao corpo hídrico (SCHOFFEL, 2009; HELFER et al., 2011). Essa técnica poderia fazer parte de um suposto planejamento dos órgãos que monitoram e gerenciam o reservatório.

A utilização de plantas aquáticas de folhas flutuantes (Cenário C3) foi à técnica com menor percentual de redução do volume evaporado (cerca de 15\%) comparado com o volume evaporado observado. Além do mais, a mesma apresenta alto custo de manutenção e de impacto no corpo hídrico (MARINHO et al., 2015; SILANS, 2003). A Figura 10 apresenta os volumes de água do reservatório São Gonçalo obtido com a simulação de cada cenário analisado. Tem-se que em todos os cenários analisados o volume de água do reservatório é superior ao volume de água observado, devido à diminuição do volume de água evaporado.

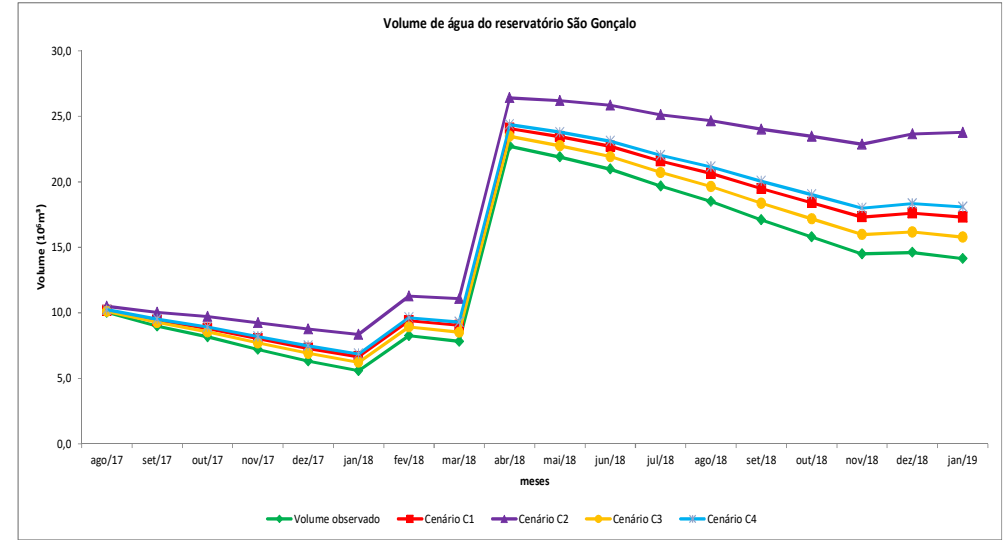

Figura 10: Volume de água do reservatório São Gonçalo para cada cenário analisado.

Destaque-se, novamente, o uso de bolas de polietileno (Cenário C2), cuja diferença do volume final de água do reservatório com o volume de água observado foi de cerca 9,6 milhões de $\mathrm{m}^{3}$ (cerca de $22 \%$ da capacidade de armazenamento do reservatório). A área do espelho d'água do reservatório, nesse cenário, situou-se entre 1,84 a 4,19 km². Tem-se que o custo de implementação e manutenção dessa técnica está diretamente relacionada à área do espelho d'água do reservatório, de modo que, para a efetividade dos resultados seria necessário repor as bolas de polietileno à medida que a área do espelho d'água aumentasse, aumentando assim, os custos de manutenção.

O uso de filmes monomoleculares de álcoois gordurosos (Cenário C4)conseguiu aumentar o volume final de água do reservatório em cerca de 3,9 milhões de $\mathrm{m}^{3}$ (cerca de $9 \%$ da capacidade de armazenamento do reservatório). Entretanto, tal técnica apresenta o mesmo problema das bolas de polietileno à medida que a área do espelho d'água aumenta, também aumentam os seus custos de manutenção.

A técnica de quebra vento (Cenário $\mathrm{C} 1$ ) aumentou o volume final de água do reservatório em cerca de 3,2 milhões de $\mathrm{m}^{3}$ (cerca de $7 \%$ da capacidade de armazenamento do reservatório). A vantagem desta técnica está no fato da mesma não está relacionada com a área do espelho d'água do reservatório, de modo que o aumento a área do espelho d'água não aumentará seu custo de manutenção.

A utilização de plantas aquáticas de folhas flutuantes (Cenário C3) além de apresentar o menor aumento do volume final de água em comparação com o volume final de água observado (cerca de 1,6 milhões de $\mathrm{m}^{3}$ ) tem os mesmos problemas do uso de bolas de polietileno e dos filmes monomoleculares de 
álcoois gordurosos.

Avaliando o período de setembro de 2017 a março de 2018 (período no qual o volume de água observado do reservatório esteve abaixo de 10 milhões de $\mathrm{m}^{3}$ ) se destaque, novamente, o uso de bolas de polietileno (Cenário C2)não havendo diferença significativa no volume de água do reservatório com a utilização das demais técnicas de redução da evaporação. Nesse caso, a área média do espelho d'água foi cerca de $33 \%$ menor do que observado em todo período, o que justificaria o uso das bolas de polietileno devido ao menor custo de implementação.

\section{CONCLUSÕES}

A análise das diferentes técnicas de redução de evaporação, em reservatórios de água nas regiões semiáridas possibilitou concluir que esses métodos podem ser empregados como mais uma ferramenta no auxílio da gestão dos recursos hídricos, em bacias hidrográficas em regiões semiáridas. As análises realizadas possibilitam elencar vantagens e desvantagens, bem como, nuances e peculiaridades intrínsecas a cada uma das técnicas descritas e estudadas.

O uso das bolas de polietileno, apesar de ser a técnica com melhor índice de redução da evaporação, é recomendável quando o reservatório apresenta baixos níveis do volume de água, devido ao seu maior custo de implementação e manutenção. A técnica de quebra vento apresentou um valor satisfatório de redução da evaporação, sendo recomendada para a região em estudo devido ao seu baixo custo implementação e manutenção, não ocasionando impactos ao corpo hídrico.

Os resultados apresentados neste estudo evidenciam a necessidade de novos estudos que possibilitem determinar um nível de água no reservatório a partir das condições financeiras dos órgãos de gestão. Por fim, constata-se que a aplicação de algumas dessas técnicas de forma isolada ou em conjunto, dependerá da peculiaridade de cada situação. Dessa forma, a escolha da melhor técnica a ser utilizada maximizará a oferta de água no futuro, de forma mais sustentável, eficaz, eficiente e ambiental.

\section{REFERÊNCIAS}

ABRANTES, G. G. A.. Suspensão judicial das outorgas do direito de uso da água da bacia hidráulica ao açude de São Gonçalo, Sousa/PB: Uma Análise Jurídico-Hídrica. Dissertação (Mestrado em Sistemas Agroindustriais) Universidade Federal de Campina Grande, Pombal, 2017.

AESA. Agencia Executiva de Gestão das Águas do Estado da Paraíba. Volume diário dos principais açudes. João Pessoa: AESA, 2019.

ANA. Agência Nacional de Águas. Conjuntura dos recursos hídricos no Brasil 2018: informe anual: versão atualizada. Brasília: ANA, 2019.

ALBUQUERQUE JUNIOR, D. M.. A invenção do Nordeste e outras artes. 4 ed. São Paulo: Cortez, 2009.

ARAÚJO, A. P. B.; COSTA, R. N. T.; LACERDA, C. F.; GHEYI, H. R.. Análise econômica do processo de recuperação de um solo sódico no Perímetro Irrigado de Curu-Pentecoste/CE.
Revista Brasileira de Engenharia Agrícola e Ambiental, v.15, n.4, p.377-382, 2011. DOI: http://dx.doi.org/10.1590/S141543662011000400008

BATISTA, R. L.. Planejamento da utilização da água de um sistema hídrico: Um estudo de caso no reservatório São Gonçalo, Sousa/PB. Monografia (Graduação em Administração) - Universidade Federal de Campina Grande, Sousa, 2013.

BLEVINS, G.; SHUTTERSTOCK, R.. Imagem bolas flutuantes utilizadas como redutor de evaporação na Califórnia-EUA. National Geographic, Washington, v.8, 2015.

CRAIG, I.; ARAVINTHAN, V.; BAILLIE, C.; BESWICK, A.;TURNBULL, D.; BARNES, G.; BRADBURY, R.; CONNELL, L.; COOP, P.; FELLOWS, C.; FITZMAURICE, L.; FOLEY, J.; HANCOCK, N.; LAMB, D.; MORRISON, P.; MISRA, R.; MOSSAD, R.; PITTAWAY, P.; PRIME, E.; REES, S.; SCHMIDT, E.; SOLOMON, D.; SYMES, T.. Evaporation, seepage and water 
quality management in storage dams: A review of research methods. Environmental Health, v.7, n.3, 2007

CONCEIÇÃO, M. A. F.. Critérios para instalação de quebraventos. Brasília: EMBRAPA, 1986.

FRANÇA, F. M. C.; OLIVEIRA, J. B.. Quebra-ventos na propriedade agrícola. Fortaleza: Secretária de Recursos Hídricos, 2010.

HELFER, F.; LEMCKERT, C.; ZHANG, H.. Investigating Techniques to Reduce Evaporation from Small Reservoirs in Australia. In: CONGRESSO MUNDIAL DA SIDH, 34. Anais. Brisbane, 2011

GHEYI, H. R.; PAZ, V. P. S.; MEDEIROS, S. S.;GALVÃO, C. O.. Recursos Hídricos em regiões semiáridas. Cruz das Almas: Universidade Federal do Recôncavo da Bahia, 2012.

LEAL, A. C.. Quebra-ventos arbóreos: aspectos fundamentais de uma técnica altamente promissora. Curitiba: IAPAR, 1986.

MARINHO, F. J. L.; AGUIAR, R. L.; UCHOA, R. T.; LEITE, S. L.; NASCIMENTO, A. F.. Mecanismo redutor de evapotranspiração em manancial hídrico localizado no semiárido Paraibano. Enciclopédia Biosfera, Goiânia, v.11, n.20, p.94-102, 2015.

VERDI, M.. Imagem plantas aquáticas, Nymphoides indica (L.) Kuntze. Porto Alegre: UFRGS, 2012.

MELO, J. C.. O fenômeno EL Niño e as secas no Nordeste do Brasil. Raízes, v.18, n.20, p.13-21, 1999.

MOLLE, F.; CADIER, E.. Manual do pequeno açude. Recife: SUDENE-ORSTOM, 1992.

MTEC. Primeira-usina-solar flutuante do brasil fica em propriedade rural em goiás. Canal Jornal da Bioenergia, n.128, p.24-26, 2017.

NICODEMO, M. L. F.. As árvores nos sistemas de produção agropecuários. São Carlos: EMBRAPA, 2006.

OECD. Governança dos Recursos Hídricos no Brasil. France: OECD, 2015. DOI:

http://dx.doi.org/10.1787/9789264238169-pt
OLIVEIRA, G. M.; LEITÃO, M. M. V. B. R.; GALVÃO, C. O.; LEITÃO, T. H. V.. Estimativa da Evaporação e Analise de Uso do Coeficiente ( $\mathrm{kp}$ ) do Tanque 'Classe A' nas Regiões do Cariri e Sertão da Paraíba. Revista Brasileira de Recursos Hídricos, v.10, n.4, p.73-83, 2005.

OLIVEIRA, P. A.. A municipalização dos serviços de saneamento: uma análise jurídico: hídrica do gerenciamento em Sousa/PB, adotado pelo departamento de águas, esgotos e saneamento ambiental - DAESA. Dissertação (Mestrado em Recursos Naturais) - Universidade Federal de Campina Grande, Campina Grande, 2015.

REBOUÇAS, A. C.; MARINHO, M. E.. Hidrologia das secas: Nordeste do Brasil. Recife: SUDENE, 1976.

SAGGAÏ, S.; BOUTOUTAOU, D.; HANCOCK, H.; BACHI, O. E. Evaporation Reduction in Water Resources: Effect of Hexadecanol Concentration on Evaporation Rate under Algerian Arid Conditions. In: INTERNATIONAL CONFERENCE ON GEOLOGICAL AND ENVIRONMENTAL SCIENCES, 2/3. Anais. Singapore: IPCBEE, 2014. DOI: http://dx.doi.org/10.7763/IPCBEE

SANTOS, V. S.; NOBREGA, A. K. Q.. Análise multicriterial no auxílio de tomada de decisão: Estudo de caso no reservatório São Gonçalo, Paraíba. Revista Verde de Agroecologia e Desenvolvimento Sustentável, v.12, n.5, p.837-842, 2017. DOI: http://dx.doi.org/10.18378/rvads

SCHOFFEL, E. R.. Importância agroecológica dos ventos: quebra-ventos. Pelotas: Universidade Federal de Pelotas, 2009.

SCIENTEC. Associação para Desenvolvimento da Ciência e Tecnologia. Plano Diretor de Recursos Hídricos da Paraíba: Bacias do Rio Piancó e do Alto Piranhas. João Pessoa: SCIENTEC, 1997.

SILANS, A. M. B.. Redução de evaporação de açudes o estado da arte. RBRH, v.8, n.2, p.101-109, 2003. DOI: http://dx.doi.org/10.21168

SUASSUNA, J.. A pequena e média açudagem no semiárido nordestino: uso da água na produção de alimentos. 2002.

VILLA, M. A.. Vida e morte no sertão: história das secas no Nordeste nos séculos XIX e XX. São Paulo: Ática, 2000.

A CBPC - Companhia Brasileira de Produção Científica (CNPJ: 11.221.422/0001-03) detém os direitos materiais desta publicação. Os direitos referem-se à publicação do trabalho em qualquer parte do mundo, incluindo os direitos às renovações, expansões e disseminações da contribuição, bem como outros direitos subsidiários. Todos os trabalhos publicados eletronicamente poderão posteriormente ser publicados em coletâneas impressas sob coordenação da Sustenere Publishing, da Companhia Brasileira de Produção Científica e seus parceiros autorizados. Os (as) autores (as) preservam os direitos autorais, mas não têm permissão para a publicação da contribuição em outro meio, impresso ou digital, em português ou em tradução. 